\author{
Fatih Oznurhan*, Arife Kapdan \\ and Burak Buldur \\ Cumhuriyet University Faculty of Dentistry \\ Department of Pediatric Dentistry, Turkey \\ Dates: Received: 22 October, 2014; Accepted: 08 \\ January, 2015; Published: 10 January, 2015 \\ *Corresponding author: Fatih Oznurhan, \\ Cumhuriyet Üniversitesi Diș Hekimliği Fakültesi \\ Pedodonti Anabilim Dalı 58140, Kampüs- Sivas/ \\ Turkey, Tel: 0090346 2191010/3103; Fax: 0000 \\ 346 2191237; E-mail: fatihozn@hotmail.com \\ www.peertechz.com \\ ISSN: 2394-8418
}

Keywords: Microtensile test; Two layer applications; Seventh generation adhesives

\section{Research Article \\ Microtensile Bond Strength of One vs Two Layer Applications of Three Disposable Seventh Generation Adhesives}

\section{Abstract}

Objectives: The aim of this in vitro study was to compare the microtensile bond strength ( $\mu$ TBS) of single versus two layers of three different $7^{\text {th }}$ generation adhesives.

Materials and Methods: One third of the human molar teeth from the coronal portion was removed and smear layer was created on these surfaces by using Silicone carbide paper. Adper Easy Bond (AEB), ClearfilS3 bond Single Dose (CS3) and Optibond Unidose (OB) were applied to flat dentin according to the manufacturer's instructions. Six groups; Group1: single application of AEB, Group2: twice application of AEB Group3: single application of CS3, Group4: twice application of CS3 Bond Group5: single application of $\mathrm{OB}$, Group6: twice application of $\mathrm{OB}$, were obtained. After applying adhesive, resin composite crowns were build up in $1 \mathrm{~mm}$ increments up to $5 \mathrm{~mm}$. After storage in distillated water for 24 hour (h), the specimens were sectioned to sticks and 15 sticks were obtained for each group. The sticks were stressed in tension until failure to see the microtensile bond strength values using a microtensile testing machine and the data were recorded. After recording data in SPSS 15.0, statistical analyses were made with ANOVA, Independent Sample T test and Tukey's post-hoc test at 0.05 level of significance.

Results: Significant differences were not found among the G1, G3, G5 ( $p>0.05$ ). G6 exhibited significantly higher $\mu$ TBS compared to the $G 2$ and $G 4(p<0.001)$. No significant differences were found among the groups regarding the failure types between cohesive or adhesive $(p>0.05)$. Lower $\mu$ TBS values were observed in two layer application when compared to the one layer application of AEB and CS3. G6 resulted in significantly higher $\mu$ TBS values compared to $G 5(p<0.001)$.

Conclusion: The results of the current investigation showed that two layer applications would be beneficial depending on the composition of adhesive and dentin substrate.

\section{Introduction}

One of the important criteria for clinical success of composite restorative materials is the effectiveness and durability of the bonded interface. After placing composite restorative material on the preparation the material encounters some problems like thermal and mechanical stresses of oral environment. These factors affect the durability of the restorative material $[1,2]$. In this step successful adhesion to dental hard tissues becomes a mandatory requirement. Adhesive systems are used to improve the restorative materials durability. To improve the adhesion to dental hard tissues, there are three-step, two-step and one-step adhesive systems are available. The adhesive bonding techniques are developing rapidly to facilitate handling. The latest generation all-in-one adhesive have combined these steps into a single-step application for simpler and faster application [3-6]. All-in-one adhesive are mixtures of hydrophobic and hydrophilic monomers and solvents, combining etching, priming and bonding into a single product [3,7-9]. They are mixed together immediately before use and then applied to tooth substrate and some of them were presented as a mixture of these adhesives. It was reported that all-in-one adhesives showed relatively low bond strengths in their study [10]. The authors attributed the decreased performance associated with factors like applying a thin coating, phase separation and use of hydrophilic monomers like hydroxyethylmethacrilate (HEMA) [11]. HEMA is a hydrophilic monomer and presents in these systems. The authors suggested the removal of the HEMA from these adhesives to minimize the water sorption. Studies showed a positive correlation between water sorption and the degree of hydrophilicity of these adhesives $[7,12]$ but it was suggested that the $10 \%$ of HEMA would be beneficial for the performance of these adhesives [13].

Because of producing a thin layer, the application of these adhesives in two layers instead of one layer has been widely recommended by the authors and manufacturers to improve their clinical efficiency. Applying an additional adhesive layer can increase acidic monomer concentration and this may lead to improve the demineralization effect, hybrid layer quality and better micromechanical bonding $[4,8,10,14]$.

The objective of this study was to determine microtensile bond strength of two different application modes (one or two layers) of three disposable seventh generation adhesives that will be useful in clinical practice. 


\section{Materials and Methods}

Twelve extracted human third molar teeth were used in this study. The teeth were stored in distillated water and used within one month. One third of the teeth from coronal portion were removed using Isomet low speed diamond saw (Isomet, Buehler, Lake Bluff, IL, USA). A stereomicroscope was used to check for the absence of enamel and pulp tissue one the resultant substrate. A smear layer was created on these surfaces by using 600 grit silicone carbide paper under water [10]. Twelve teeth were randomly divided into six groups including;

Group 1: One layer application of AEB

Group 2: Two layer application of AEB

Group 3: One layer application of CS3

Group 4: Two layer application of CS3

Group 5: One layer application of OB

Group 6: Two layer application of $\mathrm{OB}$

Bonding procedures of group 1-2: AEB (3M ESPE, Seefeld, Germany) was used for Group 1-2. For Group 1; the bond was applied for total of 20 second (s), dried for $5 \mathrm{~s}$ and light cured with LED curing light (Blue phase, Ivoclar Vivadent) for 10 seconds, according to manufacturer' instructions. In Group 2, after following same procedures, a second layer was applied additionally and lightcured in a similar manner.

Bonding procedures of group 3-4: CS3 (Kuraray Medical Inc, Japan) was used for Group 3-4. For Group 3; The bond was applied for $20 \mathrm{~s}$, dried with high pressure airflow for $5 \mathrm{~s}$ and light-cured for $10 \mathrm{~s}$, according to manufacturer' instructions. In Group 4, after following same procedures, a second layer was applied additionally and lightcured in a similar manner.

Bonding procedures of group 5-6: OB (Kerr, Italy) was used for group 5-6. For group 5, the bond was applied for 20s, gently dried and light cured for 10s. In Group 6 after following same procedures, a second layer was applied additionally and light-cured in a similar manner. The compositions of the three bonds are shown in (Table 1).

\section{Specimen preparation and microtensile testing}

After applying adhesive, resin composite crowns (Tetric N-Ceram, Ivoclar Vivadent, Liechtenstein) were built up in $1 \mathrm{~mm}$ increments up to $5 \mathrm{~mm}$. The teeth were stored in distilled water for $24 \mathrm{~h}$.

At the end of $24 \mathrm{~h}$ microtensile testing was employed using the non-trimming technique. Each tooth was sectioned in $\mathrm{x}$ and $\mathrm{y}$ direction with a slow-speed saw under water cooling into multiple 0.7 $\mathrm{mm} 2-1 \mathrm{~mm} 2$ beams. The cross-sectional areas and remaining dentin thickness of the selected specimens were measured using a digital caliper exact to $0.01 \mathrm{~mm}$. For each group 15 sticks were obtained. The sticks were stored in distilled water for $24 \mathrm{~h}$. Sticks were fixed to the microtensile device with cyonoacrylate adhesive plus an accelerator (Zapit, Dental Ventures of America, Corona, CA, USA) to see the early effects of adhesives on $\mu$ TBS. The specimens were stressed in tension until failure using a microtensile testing machine (LF Plus, LLOYD Instruments, Ametek Inc., England) at a crosshead speed of $0.5 \mathrm{~mm} / \mathrm{min}$, and the microtensile bond strength ( $\mu$ TBS) was calculated and expressed in MPa.

After microtensile testing, the fracture surfaces of all specimens were examined using a stereomicroscope (Nikon SMZ 800, Nikon Corporation, Tokyo, Japan) to determine the mode of failure at $40 \mathrm{x}$ magnification. The failure modes were classified as adhesive failure or cohesive failure.

\section{Statistical Analysis}

After recording the data, the results were subjected to statistical analysis, using the software Statistical Packages for Social Sciences for Windows 15.0 (SPSS Inc., Chicago, IL, USA). The confidence level was set at $95 \%$. For inter group comparisons, in order to obtain differences between the adhesive system (AEB, CS3 and OB), number of layers ( 1 or 2) and interactions among them, a two-way analysis of variance (ANOVA) was used. Also, to analyze the difference of the mean MPa values from each other, Tukey's post-hoc test was applied. For intra group comparisons (for each adhesive system) between the number of layer (1 or 2), the Independent Sample t test was used. Failure modes were given as percentages for each failure type.

\section{Results}

The actual bond strength values were $20.77 \pm 6.79 \mathrm{MPa}$ for G1, $16.05 \pm 3.64 \mathrm{MPa}$ for $\mathrm{G} 2,22.36 \pm 7.95 \mathrm{MPa}$ for $\mathrm{G} 3,21.47 \pm 5.86$ $\mathrm{MPa}$ for G4, 20.24 $\pm 9.73 \mathrm{MPa}$ for G5, and 40.28 $\pm 12.93 \mathrm{MPa}$ for G6. Significant interaction between the factors (adhesive system and number of applications) were found $(\mathrm{p}<0.0001)$. No significant differences were found among the groups in $\mathrm{G} 1, \mathrm{G} 3$ and $\mathrm{G} 5$ ( $\mathrm{p}=0.767$ ). G6 exhibited significantly higher bond strengths compared to the G4 and G2 respectively $(\mathrm{p}<0.0001)$. According to the intra group comparisons, lower bond strength values were observed in $\mathrm{G} 2$ to $\mathrm{G} 1(\mathrm{p}=0.025)$ and $\mathrm{G} 4$ to $\mathrm{G} 3(\mathrm{p}=0.731)$. However, G6 resulted in significantly higher bond strength values to $\mathrm{G} 5(\mathrm{p}<0.0001)$ (Table 2 , Table 3).

Table 1: The Composition of Adhesive Systems.

\begin{tabular}{|l|l|l|}
\hline Material & Composition & Manufacturer \\
\hline $\begin{array}{l}\text { Adper Easy Bond } \\
\text { (AEB) }\end{array}$ & $\begin{array}{l}\text { HEMA, Bis-GMA, methacrylated phosphoric esters, hexanidol dimethacrylate, methacrylate functionalized polyalkenoic } \\
\text { acid, camphorquinone, ethanol, water, silica filler, stabilizer }\end{array}$ & 3M \\
\hline $\begin{array}{l}\text { Optibond Unidose } \\
\text { (OB) }\end{array}$ & GPDM, GDM, HEMA, Bis-GMA, water, ethanol, acetone, silica filter, CQ, sodium hexafluorosilicate \\
\hline $\begin{array}{l}\text { Clearfil S3 } \\
\text { (CS3) }\end{array}$ & MDP, HEMA, Bis-GMA, water, acetone, silinated colloidal silica, CQ & KERR \\
\hline
\end{tabular}

Abbreviations: HEMA; hyroxyethylmethacrylate, Bis-GMA; bisfenol A glycidyl metacrylate, MDP; methacryloyloxydecyl dihydrogen phosphate, CQ; camphoroquinone, GDMP; glycerolphosphatedimethacrylate, GDM; glycerol dimethacrylate 
Table 2: Micro-tensile bond strength values (MPa) (mean \pm sd) for each adhesive system and number of layers.

\begin{tabular}{|l|c|c|}
\hline Groups & $\begin{array}{c}\text { One layer } \\
(\mathbf{n = 1 5}) \mathrm{MPa}(\text { mean } \pm \mathbf{s d})\end{array}$ & $\begin{array}{c}\text { Two layers } \\
(\mathbf{n = 1 5}) \mathrm{MPa}(\text { mean } \pm \mathbf{s d})\end{array}$ \\
\hline Adper & $20.77 \pm 6.79^{\mathrm{A}, \mathrm{a}}$ & $16.05 \pm 3.64^{\mathrm{A}, \mathrm{b}}$ \\
\hline Clearfil & $22.36 \pm 7.95^{\mathrm{A}, \mathrm{a}}$ & $21.47 \pm 5.86^{\mathrm{A}, \mathrm{a}}$ \\
\hline Optibond & $20.24 \pm 9.73^{\mathrm{A}, \mathrm{a}}$ & $40.28 \pm 12.93^{\mathrm{B}, \mathrm{b}}$ \\
\hline
\end{tabular}

*In each column different superscript capital letter indicate significant difference whereas same capital letters indicate no significant differences among the groups in each layer (number of layer) for inter group comparisons ( $p>0.05)$. In each row superscript lower case letters indicate significant differences $(p<0.05)$ whereas same lower case letters indicate no significant differences between one and two layer applications for intra group comparisons. ( $p>0.05)$.

Table 3: Multiple comparisons of the groups.

\begin{tabular}{|l|c|c|}
\hline GROUP & GROUP & SIGNIFICANCE \\
\hline \multirow{2}{*}{ One layer } & ADPER CLEARFIL &, 859 \\
& OPTIBOND &, 983 \\
\hline & CLEARFIL ADPER &, 859 \\
& OPTIBOND &, 763 \\
\hline \multirow{2}{*}{ Two layer } & OPTIBOND ADPER &, 983 \\
\hline \multirow{3}{*}{ CLEARFIL } &, 763 \\
\hline & ADPER CLEARFIL &, 198 \\
& OPTIBOND &, $000^{*}$ \\
\hline & CLEARFIL ADPER &, 198 \\
& OPTIBOND &, $000^{*}$ \\
\hline & OPTIBOND ADPER &, $000^{*}$ \\
\hline
\end{tabular}

*the mean difference is significant at the .05 level

According to the one layer bonding findings, significant differences were not found among the groups (G1, G3, G5) ( p >0.05). No significant differences were found among the groups in either one and two layers regarding failure types $(\mathrm{p}>0.05)$. No significant differences were found between the one layer and two layers regarding failure types $(\mathrm{p}>0.05)$.

AEB showed $100 \%$ adhesive failure in either one or two layer applications, CS3 exhibited $100 \%$ adhesive failure in one layer applications and $20 \%$ cohesive $80 \%$ adhesive failures in two layer applications. OB showed 100\% adhesive failure in one layer applications and $33.3 \%$ cohesive and $66.7 \%$ adhesive failure in two layers applications.

\section{Discussion}

When a composite material is placed into the cavity, all dentists want an effective and durable filling material in the long term. All researches in this field focus on finding out an effective material that provides an efficient and durable restorative material in oral cavity [15]. Adhesive systems are one of the crucial steps in this stage that provides the materials effectiveness and durability in long term. All-in-one adhesive systems are the latest generation that provides simpler and faster application and the disposable, unit doses of these materials provides infection control. In this study microtensile bond strengths of three disposable all-in-one adhesives were tested.

$\mu \mathrm{TBS}$ of these adhesives showed no statically differences in one layer applications. AEB showed adhesive failures in the percent of $100 \%$. The mean values of $\mu$ TBS for AEB were $20.77 \pm 6.79 \mathrm{MPa}$ in one layer and $16.05 \pm 3.64 \mathrm{MPa}$ in two layer application. In agreement with Belli et al. [14] AEB failure types showed adhesive failure. In AEB group one layer application of this adhesive showed significantly higher $\mu$ TBS values than two layer applications.

G1 showed significant differences to G2. $\mu$ TBS of two layer application of AEB showed a decrease in MPa values. According to the authors [14-18] the AEB showed more acidic patterns and this may lead a deep penetration of the dentin substrate and showed high values of $\mu$ TBS. In this study it was found that $\mu$ TBS of one layer application of this adhesive was significantly different from two layer applications and the authors claimed that it was hard to obtain sticks from G2 specimens. Belli et al. [14] found out that multiple application of AEB did not affect the $\mu$ TBS values but in this study $\mu$ TBS values decreased. The reason of the decreased $\mu$ TBS might be affected by the thickness of the adhesives but this effect of adhesives composition and the dentin substrate had greater affects on tensile bond strength.

The mean values of $\mu$ TBS for CS3 were $22.36 \pm 7.95 \mathrm{MPa}$ in one layer and $21.47 \pm 5.86 \mathrm{MPa}$ in two layer application and showed no statically differences. The bond strength values were decreased in G4 when compared with G3. Belli et al. [14] concluded that additional layers of CS3 could be beneficial but according to results of this study there was no significant differences between G3 and G4. The failure types of G4 showed $20 \%$ cohesive and $80 \%$ adhesive failures.

The results of OB were similar to AEB and CS3 when one layer was applied but there were significantly differences in two layer application of $\mathrm{OB}$. The mean values of $\mu \mathrm{TBS}$ in one layer application were $20.24 \pm 9.73 \mathrm{MPa}$ but there was a great increase in to layer application, $40.28 \pm 12.93 \mathrm{MPa}$. The failure types of the $\mathrm{OB}$ are also different to AEB and CS3 that showed $33.3 \%$ cohesive failure and $66.7 \%$ adhesive failure.

Felizardo et al. [8], Pashley et al. [10], and Belli et al. [14] concluded that two layer application of the adhesives would be beneficial but in this study $\mu$ TBS values were G1 $>$ G2, G5 $<$ G6 and no statically differences between G3 and G4. Silva et al. [19] and Frankenberger et al. [5] found out that the additional adhesive application did not increase the $\mu$ TBS values but in contrast to the authors G6 showed increased $\mu$ TBS values, significantly.

For G6, Optibond showed increased $\mu$ TBS values after two layer application. The most possible explanation of this result is the likely to rely on the composition of these materials. Poptani et al. [20] described the highest values due to DMA molecule which promotes chemical bonding to hydroxyapatite in dentin. When adhesive first applied the solvents of the adhesives evaporates and the concentration of the monomers increased for each layer and thereby the quality of hybrid layer improves. Acetone is a solvent and presented with ethanol in optibond [14,20,21]. Two of them may balance the solvent evaporation without dehydrating dentin, because acetone volatilizes rapidly and dehydrates the dentin and ethanol ensures the wetness of the substrate. The surfactant monomers may facilitate the penetration of hydrophobic components into dentin, reducing phase separation [7] and this property seems to contribute to a complete inter diffusion of the system all over the etched area.

HEMA which is a hydrophilic monomer incorporated in the 
evaluated adhesives and plays an important role in preventing phase-separation reactions in all-in-one adhesive systems. HEMA containing one step self-etch adhesives showed water sorption. When water sorption increases, tensile bond strengths decreased over time and water sorption at resin dentin interface would lead to failures $[9,14,18,22]$. As the sticks were stored in distilled water for $24 \mathrm{~h}$, water storage or thermo cycling was not done in this study. One of the limitations of this study was that, water storage or thermo cycling did not planned for this study to see the early effects of adhesives on $\mu \mathrm{TBS}$.

Another limitation of this study is that the statistical power may be inadequate for dentists to judge whether differences in outcome measures are statistically significant [23]. The other limitation of this study is that being an in vitro study it cannot reproduce the effects of oral environment and factors like saliva, bite forces, oral cavity temperature changes were not taken into account.

The fundamental principle of adhesion is to obtain the micromechanical bonding. To investigate the efficiency of the micromechanical bonding, clinical trials are needed. Clinical trials test the restorative materials to evaluate the effects of some variables in the oral environment to maintain of in vitro studies.

\section{Conclusion}

The results of the current investigation showed that two layer applications would be beneficial depending on the composition of adhesive and dentin substrate but in vivo studies are needed for reliable results.

\section{References}

1. Hegde MN, Manjunath $\mathrm{J}$ (2011) Bond strength of newer dentin bonding agents in different clinical situations. Oper Dent 36: 169-176.

2. Lodovici E, Reis A, Geraldeli S, Ferracane JL, Ballester RY, et al. (2009) Does adhesive thickness affect resin-dentin bond strength after thermal/load cycling? Oper Dent 34: 58-64.

3. Oztas N, Olmez A (2005) Effects of one versus two-layer applications of self-etching adhesive to dentin of primary teeth: a SEM study. J Contemp Dent Pract 6: 18-25.

4. Reis A, Albuquerque M, Pegoraro M, Mattei G, Bauer JR, et al. (2008) Can the durability of one-step self-etch adhesives be improved by double application or by an extra layer of hydrophobic resin? J Dent 36: 309-315.

5. Frankenberger R, Perdigão J, Rosa BT, Lopes M (2001) "No-bottle" vs "multibottle" dentin adhesives--a microtensile bond strength and morphological study. Dent Mater 17: 373-380.

6. Walter R, Swift EJ Jr, Boushell LW, Braswell K (2011) Enamel and dentin bond strengths of a new self-etch adhesive system. J Esthet Restor Dent. 23: 390-396.

7. Felizardo KR, Lemos LV, de Carvalho RV, Gonini Junior A, Lopes MB, et al. (2011) Bond strength of HEMA-containing versus HEMA-free self-etch adhesive systems to dentin. Braz Dent J 22: 468-472.
8. Albuquerque M1, Pegoraro M, Mattei G, Reis A, Loguercio AD (2008) Effect of double-application or the application of a hydrophobic layer for improved efficacy of one-step self-etch systems in enamel and dentin. Operative Dentistry 33: 564-570.

9. Takahashi M, Nakajima M, Hosaka K, Ikeda M, Foxton RM, et al. (2011) Long-term evaluation of water sorption and ultimate tensile strength of HEMA-containing/-free one-step self-etch adhesives. J Dent 39: 506-512.

10. Pashley EL, Agee KA, Pashley DH, Tay FR (2002) Effects of one versus two applications of an unfilled, all-in-one adhesive on dentine bonding. J Dent 30: 83-90.

11. Inoue S, Vargas MA, Abe Y, Yoshida Y, Lambrechts $P$, et al. (2003) Microtensile bond strength of eleven contemporary adhesives to enamel. Ame J Dent 16: 329-334.

12. de Andrade e Silva SM, Carrilho MR, Marquezini Junior L, Garcia FC, Manso $A P$, et al. (2009) Effect of an additional hydrophilic versus hydrophobic coat on the quality of dentinal sealing provided by two-step etch-and-rinse adhesives. J Appl Oral Sci 17: 184-189.

13. Van Landuyt KL, Snauwaert J, Peumans M, De Munck J, Lambrechts P, et al. (2008) The role of HEMA in one-step self-etch adhesives. Dent Mater 24: 1412-1419.

14. Belli R, Sartori N, Peruchi LD, Guimarães JC, Vieira LC, et al. (2011) Effect of multiple coats of ultra-mild all-in-one adhesives on bond strength to dentin covered with two different smear layer thicknesses. J Adhes Dent 13: 507 516.

15. Delme KI, Deman PJ, De Moor RJ (2005) Microleakage of class V resin composite restorations after conventional and Er:YAG laser preparation. J Oral Rehabil 32: 676-685.

16. Grégoire G, Dabsie F, Dieng-Sarr F, Akon B, Sharrock P (2011) Solvent composition of one-step self-etch adhesives and dentine wettability. J Dent 39: 30-39.

17. Dieng-Sarr F, Sharrock P, Dabsie F, Grégoire G (2011) Modifications of the organic and mineral fractions of dental tissues following conditioning by selfetching adhesives. J Dent 39: 141-147.

18. Belli R, Sartori N, Peruchi LD, Guimarães JC, Araújo E, et al. (2011) Slow progression of dentin bond degradation during one-year water storage under simulated pulpal pressure. J Dent 38: 802-810.

19. de Silva AL, Lima DA, de Souza GM, dos Santos CT, Paulillo LA. (2006) Influence of additional adhesive application on the microtensile bond strength of adhesive systems. Oper Dent 31: 562-568.

20. Poptani B, Gohil KS, Ganjiwale J, Shukla M (2012) Microtensile dentin bond strength of fifth with five seventh-generation dentin bonding agents after thermocycling: An in vitro study. Contemp Clin Dent 3: 167-171.

21. Sánchez-Ayala A, Farias-Neto A, Vilanova LS, Gomes JC, Gomes OM (2013) Marginal microleakage of class $V$ resin-based composite restorations bonded with six one-step self-etch systems. Braz Oral Res 27: 225-230.

22. Yahagi C, Takagaki T, Sadr A, Ikeda M, Nikaido T, et al. (2012) Effect of lining with a flowable composite on internal adaptation of direct composite restorations using all-in-one adhesive systems. Dent Mater J 31: 481-488.

23. Anusavice KJ (2003) Informatics systems to assess and apply clinical research on dental restorative materials. Adv Dent Res 17: 43-48. 